\title{
Sobre Mudanças Climáticas e Agroecologia
}

\author{
Carolina Alzate Gouzy* \\ *Doutoranda em Desenvolvimento Sustentável, Universidade de Brasília, \\ Brasil.e-mail: calzateg311@gmail.com
}

NICHOLLS ESTRADA, CLARA INÉS, LEONARDO ALBERTO RÍOS OSORIO, MIGUEL ÁNGEL ALTIERI (eds). Agroecología Y Resiliencia Socioecológica: Adaptándose Al Cambio Climático. Medellín: CYTED, 2013. p 207. ISBN 978-958-8790-32-9

A REDAGRES (Red Iberoamericana de Agroecología para el Desarrollo de Sistemas Agrícolas Resilientes al Cambio Climático) e a Red Adscrita al Programa Iberoamericano de Ciencia y Tecnología para el Desarrollo (CYTED) são redes de cientistas e pesquisadores em agroecologia. Eles trabalham em países articulados à Sociedad Científica Latinoamericana de Agroecología (SOCLA). As duas redes e a SOCLA propõem-se a contribuir para a análise da mudança climática por meio do desenvolvimento de uma metodologia que permita avaliar a capacidade dos agroecossistemas de resistir e se recuperar dos eventos climáticos severos. É com esse objetivo que os editores deste volume, Clara Nicholls Estrada, Leonardo Ríos Osorio e Miguel Ángel Altieri organizaram esta coletânea de experiências e reflexões teóricas, intitulada Agroecología y resiliencia socioecológica: adaptándose al cambio climático. Eles são todos professores e investigadores de alto nível da ciência da agroecologia e membros de SOCLA.

Este volume, que reúne 13 artigos de diferentes autores envolvidos nas redes e/ou SOCLA, baseia-se em análises teóricas e experiências práticas de comunidades rurais e dos seus sistemas produtivos, localizados em sete países - Chile, Estados Unidos, Cuba, Colômbia, México, Espanha e Nicarágua- das quais se elucidam princípios e estratégias sócio-ecológicas que explicam como comunidades e sistemas produtivos conseguem se recuperar de eventos climáticos extremos.

Estes eventos climáticos, apesar de serem parte da discussão, não são o foco. O foco é mais profundo: a busca da fundamentação da resiliência sócio-ecológica através da agroecologia e dos seus princípios. Estes princípios e conceitos apresentados nos trabalhos coletados são de especial interesse para a sociedade atual, que já enfrenta problemas na agricultura, graças, entre outras razões, às mudanças nos regimes de temperatura e chuvas, comprometendo assim a segurança alimentar de inúmeras comunidades. 
Alguns casos relatados nos textos do volume tratam de entender as estratégias e a dinâmica da resiliência sócio-ecológica que estas comunidades constroem. Estes sistemas tradicionais são chamados de "patrimônio cultural mundial" no prologo, graças ao valor da sua diversidade e às suas adaptações ambientais. A seguir, sintetizam-se as relações identificadas pelos diferentes autores no texto entre conceitos como resiliência sócio-ecológica e agroecologia e seu papel no desafio da adaptação à realidade de mudança climática global.

A ameaça da mudança climática global preocupa à comunidade cientifica, já que a produção agrícola de todo o mundo poderia ser seriamente afetada com mudanças radicais nos regimes de temperaturas e chuvas, comprometendo a segurança alimentar tanto a nível local como mundial (Altieri, 2013). Muitos efeitos adversos na agricultura são silenciosos e lentos, mas nem por isso são menos importantes. Por exemplo, a erosão de solos é ligada profundamente tanto às condições locais do clima como às atuações culturais dos grupos humanos que dependem desse solo (Sicard, 2013). Outro exemplo é a incidência de pragas, já que os efeitos do aquecimento global repercutem também no comportamento das populações de organismos nocivos que coabitam nos sistemas agrícolas (Vázquez Moreno, 2013). Estes problemas não são isolados - eles também são consequência dos modelos agrícolas prevalecentes, que ajudam a deteriorar a base dos recursos naturais, reduzir o carbono nos solos e romper equilíbrios ecossistêmicos (Funes-Monzote, Márquez Serrano, \& López, 2013).

Assim, enquanto o clima está se tornando cada vez mais extremo, os sistemas agrícolas convencionais intensivos se tornam cada vez menos resistentes e mais vulneráveis. Infelizmente, o setor agrícola mais afetado, segundo as previsões, serão os agricultores mais pobres nos países em desenvolvimento (Nicholls, 2013). Contudo, existem diversos exemplos de agricultura que, embora tenham pequena escala, alcançam condições que conseguem manter a resiliência dos seus agroecossistemas.

É o que ocorre com muitas populações indígenas e camponesas que estão expostas a estas mudanças. Se é verdade que são elas mais vulneráveis por estarem intimamente dependentes dos recursos naturais em ecossistemas marginais, muitas delas estão respondendo positivamente às mudanças, demostrando inovação das comunidades e resiliência dos seus agroecossistemas (Altieri, 2013). Um exemplo é Cuba, onde os efeitos mais notáveis da mudança climática são ciclones tropicais cada vez mais frequentes, longos períodos de seca, chuvas torrenciais em períodos curtos, aumento da temperatura média anual e aumento do nível do mar, entre outras. Mas, neste país têm sido desenvolvido políticas efetivas de adaptação, redução de riscos e resposta a desastres junto aos camponeses, elas podem servir de exemplo a outros países (Funes-Monzote et al., 2013).

Por causa da evidência de problemas de insustentabilidade social e econômica na nossa sociedade, os cientistas têm desenvolvido campos disciplinares como ecologia industrial, ética ambiental, economia ecológica, ecologia cultural, ecologia política e agroecologia. Estes campos visam entender como os sistemas humanos podem levar a cabo processos adaptativos que thes permitam se ajustar às dinâmicas dos ecossistemas dentro dos que os primeiros se desenvolvem. Ríos-Osorio, Salas-Zapata e Espinosa-Alzate no quinto capitulo, chamam esses processos de resiliência sócio-ecológica. Particularmente, a agroecologia se interessa por entender a resiliência sócio-ecológica dos agroecossistemas. Vale a pena colocar aqui a definição que esses autores propõem (p. 62) para agroecossistemas: "são sistemas sócio-ecológicos constituídos por sistemas agrícolas e suas interações com os sistemas sociais e ecológicos com os quais se relacionam" ${ }^{\prime}$.

1 Tradução minha 
Por sua vez, o conceito de resiliência sócio-ecológica é abordado por vários dos autores. A seguir apontam-se componentes e características deste conceito que com frequência os autores fazem alusão. Os primeiros componentes-chave mencionados são as estratégias de organização social (redes de solidariedade, intercâmbio de alimentos etc.) utilizadas pelos agricultores para enfrentar circunstâncias difíceis impostas por eventos extremos (Nicholls, 2013). Um segundo componente essencial é a adaptação sociocultural, que indica processos mediante os quais os indivíduos e grupos humanos modificam os seus padrões de comportamento para se ajustar a novas pautas ou normas que imperam no seu meio social. Esta adaptação desenvolve-se em base às habilidades sociais presentes no grupo. Pesquisas antropológicas e agroecológicas têm demonstrado que os conhecimentos locais adquiridos e transmitidos de geração em geração permitem às populações locais lidar com fenômenos e mudanças climáticos e atmosféricos (Zuluaga Sánchez, Ruiz, \& Martínez, 2013).

Vejamos algo sobre os atores envolvidos no conceito de resilencia socio-ecologica dos agroecossistemas, de acordo com os autores da coletânea. Altieri argumenta que existem várias razoes de se encontrar maior resiliência nos sistemas agroecológicos camponeses devido à diversificação do sistema, à compensação biológica ou o efeito das medidas preventivas de saneamento e podas, à recuperação biológica por causa da maior diversidade de estratos vegetais, e a recuperação ou resiliência humana/camponesa baseada na família.

As autoras do quarto texto trazem um exemplo de uma vila na Colômbia, Marinilla. Elas asseguram que nessa vila, por meio de procesos participativos, os agricultores agroecológicos têm conseguido fortalecer a sua autonomia e participar das dinâmicas socioeconômicas e políticas locais e regionais que potencializam e defendem o seu território (Zuluaga Sánchez et al., 2013); eles poderiam ser considerarados, portanto, socioeconômicamente resilientes. Como assegura Sicard (2013), compreender as características agroecológicas dos agroecossistemas tradicionais pode ser a base para o desenho de sistemas agrícolas sócio-ecologicamente resilientes.

Um outro componente da resiliência sócio-ecológica é o maior número de interações entre os seus elementos. Essas interações costumam gerar resiliência mais forte, já que esta está diretamente relacionada com a riqueza de espécies e a possibilidade de transferência de funções ecológicas entre elas (Labrador \& Gonzálvez, 2013).

Estes elementos, sucintamente examinados aqui, são parte da análise que a agroecologia faz nos agroecossistemas que estuda. Os autores da coletânea defendem a proposta da agroecologia como estrutura para estudar a resiliência socio-ecologica, já que ela se baseia na complexidade própria dos problemas da realidade, dá conta da importância do papel dos atores envolvidos e permite integrar as diferentes formas de conhecimento necessárias para entender a complexidade dos sistemas. O enfoque agroecológico é mais sensível às complexidades das agriculturas locais, ao ampliar os objetivos e critérios agrícolas para incluir as propriedades de sustentabilidade, segurança alimentar, estabilidade biológica, conservação dos recursos naturais e equidade, junto com a produtividade.

A agroecologia pode ser definida como uma transdisciplina, já que o seu objeto de indagação, a resiliência sócio-ecológica dos agroecossistemas, não é abrangido por outras ciências. A construção de conhecimento científico sobre esse objeto implica não somente integração das disciplinas pertinentes aos agroecossistemas (ciências agrarias, naturais e sociais), mas também a integração com outras formas de conhecimento, que vêm daqueles atores que conhecem e estão envolvidos nas dinâmicas dos agroecossistemas (Ríos-Osorio et al., 2013). É por tais razoes que a agroecologia é a mais apropriada e abrangente transdiciplina para realizar estes estudos.

Não só no nível acadêmico e teórico, mas também no nível prático, a agroecologia oferece respostas antes perdidas no universo estreito da especialização do conhecimento e das práticas da 
agricultura convencional. Existem problemas ambientais relacionados à agricultura convencional que ainda não foram resolvidos, como a erosão, o desmatamento, a queda dos rendimentos, a dependência de insumos químicos, e a perda de diversidade. Por sua vez, a agroecologia pode guiar um desenvolvimento agrícola sustentável, buscando conservar os recursos naturais, manter níveis contínuos de produção, minimizar os impactos no meio ambiente, satisfazer as necessidades de renda e responder às necessidades sociais das famílias e comunidades rurais (Infante L., 2013). A agroecologia e as suas práticas podem conseguir isso por meio do entendimento e da prática dos princípios agroecológicos.

Estes princípios são amplamente citados e desenvolvidos na literatura recente e nos textos deste livro. A identificação destes princípios nos diferentes estudos citados é uma contribuição para o entendimento a fundo dos mecanismos de resiliência socioambiental que estuda a agroecologia. Este exercício de transversalização da teoria em diferentes casos convida a cientistas e agricultores à analise ajuizada da complexidade dos diversos agroecossistemas ameaçados pelas mudanças climáticas. 